\title{
Application of microarray technology for the detection of intracranial bacterial infection
}

\author{
JIANHONG SHEN $^{1}$, YIXIANG GUAN ${ }^{2}$, JIANPING ZHANG $^{2}$, JIANWU TANG $^{3}$, \\ XIAOJIAN LU ${ }^{1}$ and CHUNXIU ZHANG ${ }^{4}$
}

\author{
${ }^{1}$ Department of Neurosurgery, Affiliated Hospital of Nantong University, Nantong, Jiangsu 226001; \\ Departments of ${ }^{2}$ Surgery and ${ }^{3}$ Infectious Disease, Affiliated Haian People's Hospital of Nantong University, Haian, \\ Jiangsu 226600; ${ }^{4}$ Shanghai Biochip National Engineering Research Center, Shanghai 201203, P.R. China
}

Received July 24, 2013; Accepted November 20, 2013

DOI: 10.3892/etm.2013.1443

\begin{abstract}
The aim of this study was to assess the value of microarray technology for the detection of intracranial bacterial infection. A small gene chip was prepared based on the four pathogens commonly known to cause intracranial infection and the corresponding six types of common resistance genes in The Affiliated Hospital of Nantong University and The Affiliated Haian People's Hospital of Nantong University. Cerebrospinal fluid samples were then collected from 30 patients with clinically diagnosed intracranial infection for the detection of the bacteria and resistance genes. The results were compared with the bacterial culture and sensitivity test results from the Department of Clinical Laboratories. The laboratory bacterial culture took 4-5 days, and revealed that 12 cases were positive and 18 cases were negative for bacteria. The microarray analysis took 1 day, and bacteria and resistance genes were detected in 15 cases. The $16 \mathrm{~S}$ gene and drug resistance genes were detected in 8 cases; however, the bacterial strain was not identified. Seven cases appeared negative for bacteria and resistance genes. Microarray technology is rapid, sensitive and suitable for use in the detection of intracranial infections and other diseases for which conventional bacterial culture has a low positive rate.
\end{abstract}

\section{Introduction}

Bacterial infection of the central nervous system is a common and serious threat to human life, and requires timely and effective antibiotic treatment (1). For this to occur, a rapid and accurate detection and identification of the cerebrospinal fluid (CSF) pathogens is necessary. The diagnosis of intracranial infection mainly relies on CSF bacterial culture, which

Correspondence to: Dr Yixiang Guan, Department of Surgery, Affiliated Haian People's Hospital of Nantong University, Haian, Jiangsu 226600, P.R. China

E-mail: yixiangguancn@163.com

Key words: intracranial infection, cerebrospinal fluid, bacterial culture, microarray, drug resistance gene is considered to be the gold standard due to its high specificity $(2,3)$. However, this is a time consuming procedure, and specific bacteria are difficult to cultivate. In addition, given the influence of antibiotics, among other factors, the positive rate of CSF culture is minimal, i.e. $\sim 10 \%$ in the hospital and $10-20 \%$ in the majority of studies $(3,4)$. Therefore, the current methods of etiological examination are inadequate when compared with the advancements in clinical treatment (1). Microarray technology has the advantages of easy operation, rapid detection and the ability to simultaneously detect a large number of specific molecules. In the present study, several types of typical intracranial infection-causing pathogens and their common resistance genes were selected based on their specific DNA sequence. A small microarray was designed and prepared to study the application value of microarray technology in intracranial infection.

\section{Materials and methods}

Types of bacteria and drug resistance genes. Based on the common intracranial infection-causing bacteria indicated by the Neurosurgery Department of The Affiliated Hospital of Nantong University (Nantong, China) and The Affiliated Haian People's Hospital of Nantong University (Haian, China), the following Gram-positive and Gram-negative cocci and bacilli were used: Staphylococcus aureus, Klebsiella pneumoniae, Escherichia coli and Streptococcus pneumoniae. In addition, the six most common drug resistance genes of these four bacteria (mecA, OXA-23, SHV, CTX-M, TEM and PBP1a) were tested. This study was conducted in accordance with the Declaration of Helsinki and with approval from the Ethics Committee of the Affiliated Haian People's Hospital of Nantong University (Haian, China). Written informed consent was obtained from all participants.

Clinical specimen collection. Based on the detected stains, 30 CSF samples from patients with clinically diagnosed intracranial infection were collected between January 2010 and August 2011 at the Neurosurgery Departments of the Affiliated Hospital of Nantong University (Nantong, China) and the Affiliated Haian People's Hospital of Nantong University. Among the samples, bacterial culture revealed that 12 cases 
were positive (five for $S$. aureus, three for K. pneumoniae, two for E. coli and two for S.pneumoniae) and 18 cases were negative (the negative CSF samples within the same period were generated numbers and randomly selected). The clinical diagnosis of intracranial bacterial infection was based on the Harrison standard (5), combined with the following neurosurgical characteristics: i) Risk factors for intracranial infection, including CSF leak, open brain injury, surgery for an extended period (>4 h), >2 surgeries and external drainage of CSF; ii) clinical manifestations of fever, headache, vomiting or meningeal irritation; and iii) white blood cell count $>1.18 \times 10^{9}$ cells $/ 1$, glucose $<1.9 \mathrm{mmol} / 1$ and protein $>2.2 \mathrm{~g} / 1$, as assessed with CSF testing.

CSF bacterial culture. Loop-picked turbid CSF was inoculated on blood agar and chocolate agar plates at $35^{\circ} \mathrm{C}$ under $5 \% \mathrm{CO}_{2}$ for $24 \mathrm{~h}$.

Bacterial DNA extraction from CSF. Each CSF sample $(\sim 2 \mathrm{ml})$ was collected and centrifuged at 8,000 x $\mathrm{g}$ for $10 \mathrm{~min}$. The supernatant was then discarded and the sediment was suspended in sterile saline, prior to being subjected to centrifugation at $8,000 \mathrm{x}$ g for $10 \mathrm{~min}$. Having discarded the supernatant, a DNeasy ${ }^{\circledR}$ Blood \& Tissue kit (Qiagen GmbH, Hilden, Germany) was used. DNA lysate $(\sim 180 \mu \mathrm{l})$ was added to the sediment, the mixture was placed in a $37^{\circ} \mathrm{C}$ water bath for $30 \mathrm{~min}$ and $\sim 25 \mu \mathrm{l}$ proteinase $\mathrm{K}$ being added. The mixture was subsequently placed in a $56^{\circ} \mathrm{C}$ water bath for $30 \mathrm{~min}$ and $200 \mu \mathrm{l}$ ethanol was added using spin columns to extract the sample DNA.

Primer design and synthesis of probes. The specific DNA sequences were screened for four types of bacteria and six resistance genes from GenBank (http://www.ncbi.nlm. nih.gov/genbank/), using the software Primer Premier 5.0 (Premier Biosoft, Palo Alto, CA, USA) to design 10 pairs of PCR primers and probes (Table I). The 16S rDNA gene codes for prokaryotic ribosomal small subunit rRNA (16S rRNA) and is the most common and useful 'molecular clock' in bacterial taxonomic studies. The constant region of $16 \mathrm{~S}$ rRNA is a common feature of all bacteria (6). Therefore, based on the constant region of the $16 \mathrm{~S}$ gene found in all strains of bacteria, primers and a probe were designed as a positive reference. All primers and probes were synthesized by Shanghai Invitrogen Biotechnology Co., Ltd. (Shanghai, China).

Multiplex polymerase chain reaction (PCR). The experiments were divided into two groups (Table I). The first group underwent microbiological testing, while the second group underwent resistance gene testing with water as a negative control. The reaction system contained the following: $1.5 \mu \mathrm{l}$ buffer (10X), $0.2 \mu \mathrm{l}$ deoxyribonucleotide triphosphate (10 mmol/l), $1.0 \mu \mathrm{l}$ DNA (20 ng/ $\mu \mathrm{l}), 0.2 \mu \mathrm{l} \mathrm{Taq}$ enzyme, $0.2 \mu \mathrm{l}$ primers $x 2(20 \mu \mathrm{mol} / \mathrm{l}), 0.6 \mu \mathrm{l} \mathrm{MgCl}_{2}(25 \mathrm{mmol} / \mathrm{l})$ and $11.1 \mu \mathrm{l}$ $\mathrm{H}_{2} \mathrm{O}$. The total volume was $15 \mu 1\left(\mathrm{~T}_{\mathrm{m}}, 56^{\circ} \mathrm{C} ; 30\right.$ cycles $)$. The PCR products were analyzed using agarose gel electrophoresis ( $2 \%$ agarose; voltage, $150 \mathrm{~V}$; running time, $15 \mathrm{~min}$ ), and the bands were observed.

Microarray preparation. The PCR products were diluted to $50 \mathrm{mmol} / \mathrm{l}$ with spotting solution and added to 384-well plates

$\begin{array}{lcccccc}\text { P } & \text { P } & \text { P } & \text { P } & \text { P } & \text { P } & \text { P } \\ \text { P } & \text { SA } & \text { SA } & \text { SA } & \text { OXA-23 } & \text { OXA-23 } & \text { OXA-23 } \\ \text { P } & \text { CTX-M } & \text { CTX-M } & \text { CTX-M } & \text { N } & \text { N } & \text { N } \\ \text { P } & \text { TEM } & \text { TEM } & \text { TEM } & \text { N } & \text { N } & \text { N } \\ \text { P } & \text { N } & \text { N } & \text { N } & \text { SHV } & \text { SHV } & \text { SHV } \\ \text { P } & \text { N } & \text { N } & \text { N } & \text { N } & \text { N } & \text { N } \\ \text { P } & \text { KNP } & \text { KNP } & \text { KNP } & \text { PC } & \text { PC } & \text { PC } \\ \text { P } & \text { E.coli } & \text { E.coli } & \text { E.coli } & \text { PBP1a } & \text { PBP1a } & \text { PBP1a } \\ \text { P } & 16 \text { S } & 16 \text { S } & \text { 16S } & \text { mecA } & \text { mecA } & \text { mecA } \\ \text { P } & \text { N } & \text { N } & \text { N } & \text { B } & \text { B } & \text { B }\end{array}$

Figure 1. Arrangement picture of the bacteria and resistance gene-detecting microarray. N, negative control probe; $\mathrm{P}$, positioning probe; $\mathrm{B}$, blank control; SA, Staphylococcus aureus; KNP, Klebsiella pneumoniae; PC, Streptococcus pneumoniae; E. coli, Escherichia coli.

(Corning Life Sciences, Tewksbury, MA, USA) at $10 \mu 1$ per well. Under $60 \%$ humidity and $25^{\circ} \mathrm{C}$, contact spotting (Omni Grid $^{\text {TM }} 100$ microarray spotter; GeneMachine, USA) was performed to load the probe point to the optical level of the aldehyde modification chip (Boao Biology Co., Ltd., Beijing, China). The matrix measured $10 \times 7$, and all points were randomly arranged. Each probe set was repeated in triplicate (Fig. 1). The microarray was supplied by Shanghai Biochip Co., Ltd. (Shanghai, China) and placed in the oven during storage.

Microarray hybridization and result interpretation. The PCR products were fluorescently labeled under the following conditions: $96^{\circ} \mathrm{C}$ for $3 \mathrm{~min}$, followed by $66^{\circ} \mathrm{C}$ for $30 \mathrm{sec}$, $72^{\circ} \mathrm{C}$ for $20 \mathrm{sec}$ for 35 cycles and extension at $72^{\circ} \mathrm{C}$ for 5 min. The products were then placed in the dark at $4^{\circ} \mathrm{C}$. The fluorescently-labeled products were subjected to DNA hybridization (Thermo Hybaid Maxi 14 Hybridization Oven; Thermo Hybaid, Ulm, Germany) at $48^{\circ} \mathrm{C}$ for $2 \mathrm{~h}$. The hybridized chip was then scanned (GenePix ${ }^{\circledR}$ 4000B confocal laser scanner; Molecular Devices, LLC, Sunnyvale, CA, USA), and GenePix ${ }^{\circledR}$ Pro 6.0 Acquisition and Analysis Microarray Software (Molecular Devices, LLC) was used to assess the fluorescence signal intensity value of each probe set. The low-signal locus was removed, and values higher than the cutoff value [signal-to-noise ratio, 3.0] were deemed as a valid signal.

\section{Results}

Multiplex PCR. Ten pairs of primers were designed to amplify the corresponding target bacteria and resistance gene sequences. The PCR products were then subjected to agarose gel electrophoresis, showing clear bands of the appropriate size (Fig. 2). The results demonstrated the specification and effectiveness of the designed primer sequences.

Microarray hybridization. Following hybridization with the multiplex PCR products and specific probes, the microarray 
Table I. Sequences of multiplex polymerase chain reaction primers and microarray hybridization probes.

\begin{tabular}{|c|c|c|}
\hline $\begin{array}{l}\text { Name of bacteria and } \\
\text { resistance genes }\end{array}$ & Primer and probe sequence $\left(5^{\prime}-3^{\prime}\right)$ & Product size, bp \\
\hline Staphylococcus aureus & $\begin{array}{l}\text { Sense primer: TAAAGCGATTGATGGTGATACG } \\
\text { Antisense primer: AGCCAAGCCTTGACGAACTA } \\
\text { Probe: AGCGAGCATACGGCAATACTCGTTGACTGCCTCTTCGCTGT }\end{array}$ & 238 \\
\hline Klebsiella pneumoniae & $\begin{array}{l}\text { Sense primer: GCCTTGACCGCTGGGAAAC } \\
\text { Antisense primer: GGCGTATCCCGCAGATAAAT } \\
\text { Probe: CAACGCACTGACCATACCTACTTTGTTATTCGGGCCAAGC }\end{array}$ & 319 \\
\hline Escherichia coli & $\begin{array}{l}\text { Sense primer: CATGCGGTTCAGCCACGGTT } \\
\text { Antisense primer: GCGCCAGTATTCCGCACCAA } \\
\text { Probe: CGAATCAGTCTTGCTCATCGTCGCTATCTGGCTGACTGCTT }\end{array}$ & 471 \\
\hline Pneumococcal & $\begin{array}{l}\text { Sense primer: CATTGTCTTAGGCGGAG } \\
\text { Antisense primer: ATTGGTGTATTGACTGC } \\
\text { Probe: CGTTGCCGAGTTTCCATGTAGGTCTTTACCATAGTAGTTTTG }\end{array}$ & 679 \\
\hline $16 \mathrm{~S}$ & $\begin{array}{l}\text { Sense primer: AGGAGGTGATCCAACCGCA } \\
\text { Antisense primer: AACTGGAGGAAGGTGGGGAT } \\
\text { Probe: AGCTCACCATGTACGAACTGGGTGAATACGTTCCCGGGCCTTGT }\end{array}$ & 370 \\
\hline mecA & $\begin{array}{l}\text { Sense primer: GGCTATCGTGTCACAATCGTTGACG } \\
\text { Antisense primer: GGGTGGATAGCAGTACCTGAGCCA } \\
\text { Probe: CGTATCGACTGCATCAATCCAGATGGCAAAGATATTCAACTAACT }\end{array}$ & 170 \\
\hline OXA-23 & $\begin{array}{l}\text { Sense primer: ATGGAAGGGCGAGAAAAGG } \\
\text { Antisense primer: TTGCATGAGATCAAGACCGATA } \\
\text { Probe: AGTGGATCTTGTACGTGGACCGCAAGTTCCTGATAGACTGGGACTGCC }\end{array}$ & 127 \\
\hline SHV & $\begin{array}{l}\text { Sense primer: GCCTTGACCGCTGGGAAAC } \\
\text { Antisense primer: GGCGTATCCCGCAGATAAAT } \\
\text { Probe: CGAATCAGTCTTGCTCATCGTGTCGCCCTGCTTGGCCCGGATAAC }\end{array}$ & 319 \\
\hline CTX-M & $\begin{array}{l}\text { Sense primer: CGGGAGGCAGACTGGGTGT } \\
\text { Antisense primer: TCGGCTCGGTACGGTCGA } \\
\text { Probe: CCTGACTGCAATAGATCCTGACGGCCATCACTTTACTGGTGCTGC }\end{array}$ & 381 \\
\hline TEM & $\begin{array}{l}\text { Sense primer: GTCGCCGCATACACTATTCTCA } \\
\text { Antisense primer: CGCTCGTCGTTTGGTATGG } \\
\text { Probe: GTCAGCGAGAACATGTGTACGCGGTTAGCTCCTTCGGTCCTCCG }\end{array}$ & 258 \\
\hline PBP1a & $\begin{array}{l}\text { Sense primer: AGTATTCACTACTCAAATGC } \\
\text { Antisense primer: GCTACAAATTGAGAGGTGTT } \\
\text { Probe: CACTGAACAGCTGACATACG GGCAGCGTAAGCAGCAGCCATCT }\end{array}$ & 557 \\
\hline
\end{tabular}

showed green fluorescence at the corresponding sites (Fig. 3), whereas the negative control showed no fluorescence. As a result, the bacterial species and resistance genes were identified.

Microarray comparison with CSF culture results. The microarray procedure took one day, whereas bacterial culture and sensitivity testing took 4-5 days. A total of 12 CSF samples with positive bacterial cultures were identified as being positive for bacterial strains and resistance genes (Fig. 4A) using microarray, including five that were positive for $S$. aureus, three for K. pneumonia, two for $E$. coli and two for $S$. pneumoniae, consistent with the bacterial culture results. Among the 18 specimens that had negative bacterial culture results, bacteria and drug resistance genes were identified in a number of samples (Fig. 4B), including one sample positive for
S. aureus and two for E. coli. The $16 \mathrm{~S}$ gene without bacteria was detected in eight cases. However, the majority of these 8 cases (six) were positive for resistance genes (Fig. 4C). Samples from seven patients were without detectable $16 \mathrm{~S}$ or drug resistance genes (Fig. 4D).

\section{Discussion}

Although CSF bacterial culture is an important technique for the diagnosis of intracranial bacterial infection, the positive rate is too low and the process is time consuming $(2,7)$. These disadvantages hinder the application of CSF bacterial culture in clinical treatment; therefore, various testing methods have been proposed as a supplement or substitute for bacterial culture, for example PCR $(2,3,8)$ and immunological analyses (9). Multiplex PCR technology involves adding various 


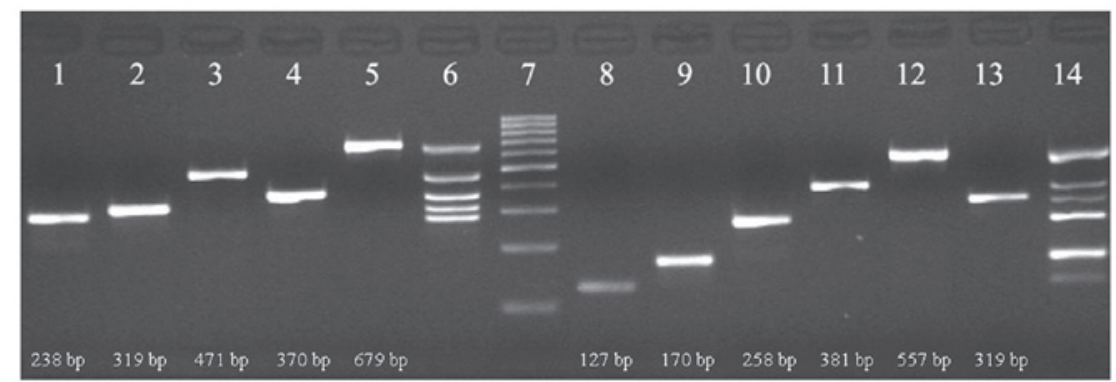

Figure 2. Detection of bacterial strains and resistance genes using electrophoresis of the PCR products. Lane 1, Staphylococcus aureus; 2, Klebsiella pneumoniae; 3, Escherichia coli; 4, 16S; 5, Streptococcus pneumoniae; 6, multiplex PCR of bacteria; 7, Marker; 8, OXA-23; 9, mecA; 10, TEM; 11, CTX-M; 12, PBP1a; 13, SHV; 14, multiplex PCR of resistance genes. The marker strips from the bottom to the top were: $100,200,300,400,500,600,700,800,900$ and 1,000 bp. PCR, polymerase chain reaction.

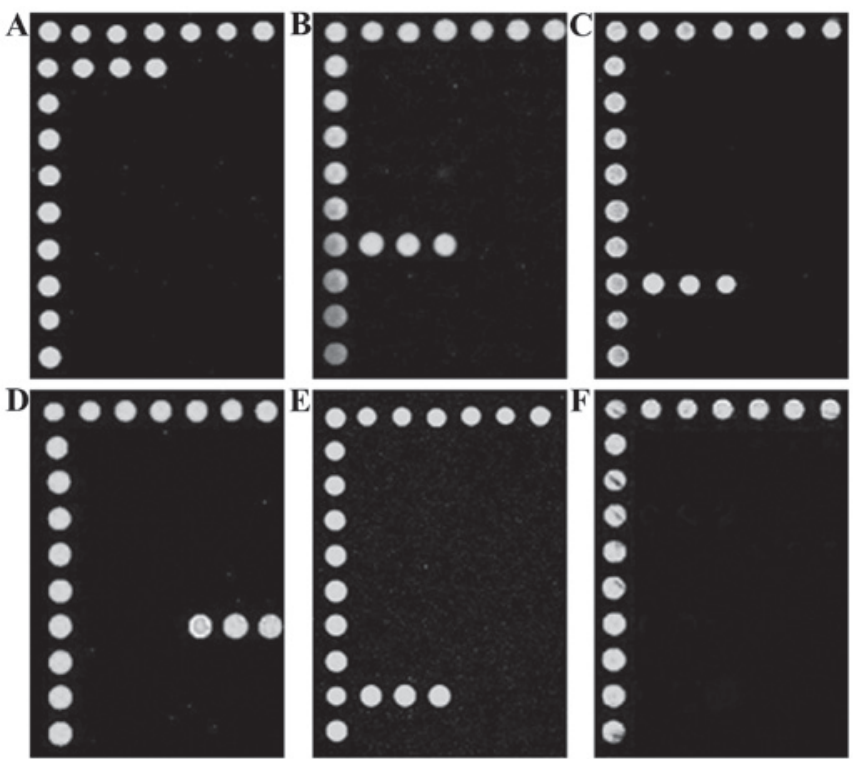

Figure 3. Identification of the bacterial species using microarray. (A) Staphylococcus aureus; (B) Klebsiella pneumoniae; (C) Escherichia coli; (D) Streptococcus pneumoniae; (E) 16S; (F) experimental water.
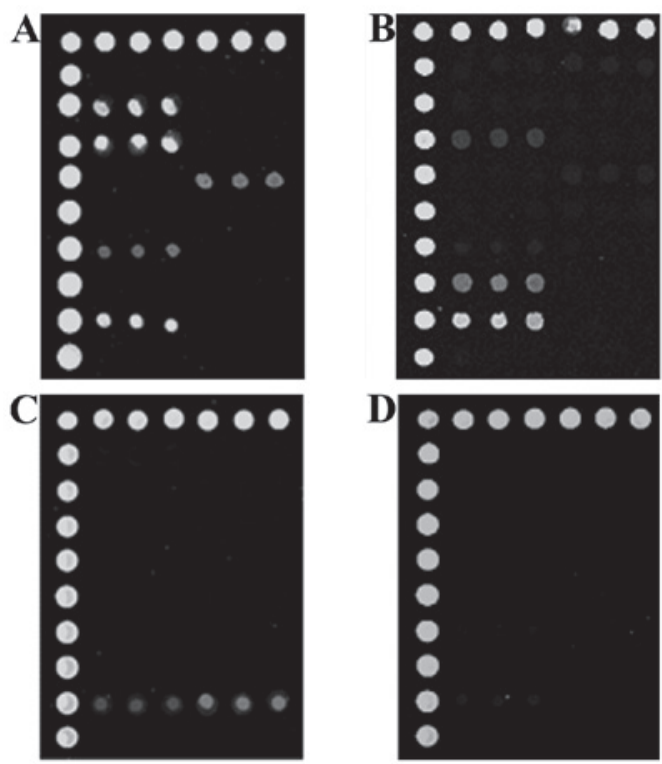

Figure 4. Examples of microarray detection. (A) Klebsiella pneumoniae, 16S, CTX-M, TEM and SHV; (B) Escherichia coli, 16S and TEM; (C) 16S and mecA; (D) negative. specific primers in the same PCR system to simultaneously detect multiple pathogens or resistance genes $(2,10)$. With regard to microarray technology, a large number of probes must be fixed onto a support to detect and analyze a variety of sample sequences (11). Since numerous pathogens cause intracranial infection, the two technologies were combined in the present study to detect four types of bacteria and six resistance genes. All experiments were performed in one day, showing that the process was an efficient means of genetic testing (12), facilitating the rapid detection of pathogens causing intracranial infection.

Twelve cases of positive bacterial culture specimens were identified to have the same strains based on the microarray results. Among the 18 cases of culture-negative specimens, 11 were shown to be positive following gene chip hybridization of the $16 \mathrm{~S}$ gene, demonstrating the presence of bacterial infection. This indicated that microarray technology had a higher sensitivity than CSF culture. Eight cases were shown to be positive for the $16 \mathrm{~S}$ gene without bacteria being identified. This may have been due to the pathogens not belonging to one of the four species included in the study design. The 15 positive specimens (12 positive in culture and 3 negative in culture but positive in microarray) showed only one result, indicating that microarray technology had a high specificity.

Among the $30 \mathrm{CSF}$ samples that were diagnosed as having intracranial bacterial infections, seven cases failed to pass the gene chip detection for the presence of bacteria. There were several possible reasons for this. The experiments were conducted using a fluorescent-labeling method to perform the gene hybridization and interpret the results. When the conventional material for the fluorescent-labeling method was used, the sensitivity was low (13). In addition, the bacterial DNA content of specific samples was too low. The required level of fluorescently-labeled DNA was not achieved, even following several amplifications. Furthermore, steric hindrance existed between the target molecule and probe, and the hybridization probe molecules affected the quality of results (14). Therefore, negative microarray results were not able to be used as a reliable indicator of a definitive negative clinical diagnosis. In addition, microarray is not recommended for patients with a high positive rate of bacterial culture, such as lung infection.

Antibiotic resistance is a common phenomenon, particularly when antibiotics are frequently used (15). Microarray technology is capable of rapidly detecting common resistance 
genes in the case of unknown bacteria, in accordance with the various resistance genes supplying direction for early clinical trials of drugs (16). TEM, CTX-M and OXA-23 are hyperspectral $\beta$-lactamases that have been associated with drug resistance to penicillin and cephalosporins (17). mecA is a type of methicillin-resistant gene, and has been associated with drug resistance to gentamicin, imipenem and cephalosporins (18). Furthermore, the KPC gene encodes carbapenem, which has been associated with drug resistance to imipenem (19). Results from the experimental detection of resistance genes corroborated with the susceptibility test results, showing the reliability of the experimental detection of resistance genes. Of course, the detection of resistance genes also has significant limitations, for it may only help to avoid the use of partial tolerant antibiotics. However, resistance gene detection is not able to guide the selection of sensitive drugs and therefore is not able to substitute for susceptibility testing. Nevertheless, in the case of culture-negative CSF, the test result of resistance genes is the only reference index available.

The small chip experiments of the current study demonstrate that microarray technology has advantages in terms of speed and sensitivity compared with traditional CSF bacterial cultures. Based on the detection of resistance genes, microarray technology also avoids the use of antibiotics as soon as possible. However, specific disadvantages, such as high cost and low sensitivity, exist. The present trends in microarray technology have three main aspects (20,21): i) High-density probe analysis; ii) microanalysis of the test samples; and iii) microanalysis of the chip matrix area. These aspects further enhance detection sensitivity and greatly reduce the cost of testing. With the development of chip technology, microarray technology shows potential for the diagnosis of bacterial culture diseases with low positive rates, such as intracranial infection.

\section{Acknowledgements}

This study was supported by the Social Development Science and Technology Project of Nantong (grant no. S10935).

\section{References}

1. Lin AL and Safdieh JE: The evaluation and management of bacterial meningitis: current practice and emerging developments. Neurologist 16: 143-151, 2010.

2. Favaro M, Savini V, Favalli C and Fontana C: A multi-target real-time PCR assay for rapid identification of meningitis-associated microorganisms. Mol Biotechnol 53: 74-79, 2013.

3. Wu HM, Cordeiro SM, Harcourt BH, et al: Accuracy of real-time PCR, Gram stain and culture for Streptococcus pneumoniae, Neisseria meningitidis and Haemophilus influenzae meningitis diagnosis. BMC Infect Dis 13: 26, 2013.
4. Srinivasan L, Pisapia JM, Shah SS, Halpern CH and Harris MC: Can broad-range $16 \mathrm{~S}$ ribosomal ribonucleic acid gene polymerase chain reactions improve the diagnosis of bacterial meningitis? A systematic review and meta-analysis. Ann Emerg Med 60: 609-620, 2012

5. Harrison PJ: Bacterial meningitis. Lancet 2: 848, 1979.

6. Santoni D and Romano-Spica V: A gzip-based algorithm to identify bacterial families by $16 \mathrm{~S}$ rRNA. Lett Appl Microbiol 42: 312-314, 2006.

7. Etyang AO, Amayo EO, Bhatt SM, Wamola IA and Maritim MC: Comparison of bedside inoculation of culture media with conventional cerebrospinal fluid culture method in patients with bacterial meningitis. East Afr Med J 86: 476-479, 2009.

8. Sanou M, Palenfo D, Bisseye C, et al: Molecular diagnosis of bacterial meningitis in Burkina Faso. Med Sante Trop 23: 93-99, 2013 (In French)

9. Ouédraogo SM, Yaméogo TM, Kyelem CG, et al: Acute bacterial meningitis with soluble antigen detected by latex particle agglutination tests at the Sourô-Sanou University Hospital of Bobo-Dioulasso (Burkina Faso). Med Sante Trop 22: 412-416, 2012 (In French).

10. Gupta S, Bandyopadhyay D, Paine SK, et al: Rapid identification of mycobacterium species with the aid of multiplex polymerase chain reaction (PCR) from clinical isolates. Open Microbiol J 4: 93-97, 2010.

11. Palka-Santini M, Pützfeld S, Cleven BE, Krönke M and Krut O: Rapid identification, virulence analysis and resistance profiling of Staphylococcus aureus by gene segment-based DNA microarrays: application to blood culture post-processing. J Microbiol Methods 68: 468-477, 2007.

12. Shi J, Wu Y, Cai M and Shang S: Rapid diagnosis of herpetic encephalitis in children by PCR-microarray technology for simultaneous detection of seven human herpes viruses. Eur J Pediatr 169: 421-425, 2010.

13. Mathias PC, Jones SI, Wu HY, et al: Improved sensitivity of DNA microarrays using photonic crystal enhanced fluorescence. Anal Chem 82: 6854-6861, 2010.

14. Southern EM: DNA microarrays. History and overview. Methods Mol Biol 170: 1-15, 2001.

15. Sengupta S, Chattopadhyay MK and Grossart HP: The multifaceted roles of antibiotics and antibiotic resistance in nature. Front Microbiol 4: 47, 2013.

16. Bruant G, Maynard C, Bekal S, et al: Development and validation of an oligonucleotide microarray for detection of multiple virulence and antimicrobial resistance genes in Escherichia coli. Appl Environ Microbiol 72: 3780-3784, 2006.

17. Chen H, Shu W, Chang X, Chen JA, Guo Y and Tan Y: The profile of antibiotics resistance and integrons of extended-spectrum beta-lactamase producing thermotolerant coliforms isolated from the Yangtze River basin in Chongqing. Environ Pollut 158: 2459-2464, 2010.

18. Gardete S, de Lencastre $\mathrm{H}$ and Tomasz A: A link in transcription between the native pbpB and the acquired mecA gene in a strain of Staphylococcus aureus. Microbiology 152: 2549-2558, 2006.

19. Papp-Wallace KM, Bethel CR, Distler AM, Kasuboski C, Taracila $\mathrm{M}$ and Bonomo RA: Inhibitor resistance in the KPC-2 beta-lactamase, a preeminent property of this class A beta-lactamase. Antimicrob Agents Chemother 54: 890-897, 2010.

20. Ahmad H, Sutherland A, Shin YS, et al: A robotics platform for automated batch fabrication of high density, microfluidics-based DNA microarrays, with applications to single cell, multiplex assays of secreted proteins. Rev Sci Instrum 82: 094301, 2011.

21. Bumgarner R: Overview of DNA microarrays: types, applications, and their future. Curr Protoc Mol Biol: 22.1.1-22.1.11, 2013. 